\title{
The Expression and Reasoning of Spatial Direction Relations Based on Lattice Arrays
}

\author{
Ping Guo Shuyuan Jia Dong Li \\ School of Computer Science, Chongqing University, Chongqing 400044, P. R. China
}

\begin{abstract}
The direction relations expression, analysis and processing are very important problems in GIS. In order to enhance the direction relations expression precision, we have given the hypo-strong direction relations set based on the human cognition, and discussed on the reasoning method based on the new direction relation expression model, and brought forward the more intuitionistic reasoning method based on the lattice arrays model. This method improved on the reasoning method of query table based on combinative table.
\end{abstract}

Keywords: Direction relation, Intelligent GIS, Lattice arrays

\section{Introduction}

Spatial relations are some relations with spatial quality between geographical entities [1]. In GIS, spatial relations mostly include topological relations, direction relations and metric relations. Direction relation describes certain ordering between objects in space, such as front, back, east, west and so on.

Spatial reasoning is a process that utilizes spatial theory and artificial intelligence for spatial objects to modeling, description and representation, and then proceeds with qualitative or quantitative analysis and process for spatial relations between spatial objects [2]. Qualitative spatial reasoning (QSR) is the important part of spatial reasoning, and it's an artificial intelligence method to process commonsensible spatial knowledge. Spatial reasoning plays an important role in the process of spatial query, spatial analysis, layout strategy and so on.

As the complexity and uncertainty exist intrinsically in spatial problems, qualitative method is adopted for the representation and reasoning of spatial relations generally in recent years. So qualitative spatial representation and reasoning become the research focus gradually [3]-[5]. However, there are few literatures that describe the qualitative reasoning about direction relation based on projection model with a neutral zone. Based on the projection model with a neutral zone for direction relation representation, this paper introduces the lattice array representation for direction relation and gives the qualitative reasoning method through combinative operation between lattice arrays.

\section{Direction model with neutral zone}

When the reference object is not the point object, the model, which uses the projection_based method around minimum bounding rectangle (MBR) of reference object [6], is a usual direction relation model. The projection-based method, applied around the reference object $X$, partitions the embedding space $\left(R^{2}\right)$ into nine mutually exclusive regions, called direction tiles (as Figure 1), whose union forms a complete partition of space. The direction tiles at the periphery correspond to the eight cardinal directions - restricted north $(\mathrm{RN})$, northeast (NE), restricted east (RE), southeast (SE), restricted south (RS), southwest (SW), restricted west (RW), and northwest (NW) - while the tile at the center, called same (SA), coincides with the minimum bounding rectangle of the reference object $X\left(\mathrm{MBR}_{\mathrm{X}}\right)$. The boundaries between any neighboring tiles have no extent. As Figure 1, SA expresses the same direction relation. Specially, when reference object is the point object the perpendicular_ horizontal projection is projection model.

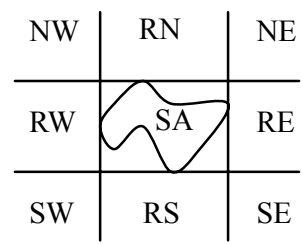

Fig 1.Projection-based direction model with neutral zone.

Definition 1: The projection-based model around the reference object $\mathrm{X}$ partitions $\mathrm{R}^{2}$ into 9 direction tiles, the cardinal direction in each tile is marked in Figure 1. According to Figure 1,we denote those 9 direction relations as $\mathrm{D}_{9}=\{\mathrm{RN}, \mathrm{NE}, \mathrm{RE}, \mathrm{SE}, \mathrm{RS}, \mathrm{SW}, \mathrm{RW}, \mathrm{NW}, \mathrm{SA}\}$, which are called strong direction relations. Each tile is denoted as strong-direction region $\mathrm{S}_{\mathrm{i}}, \mathrm{i} \in \mathrm{D}_{9}$. When the reference object cannot confuse, $\mathrm{Si}$ expresses the reference object.

We capture direction between reference object $\mathrm{X}$ and target object $\mathrm{Y}$ in the direction-relation matrix $\mathrm{D}_{x y}$, 
a $3 \times 3$ matrix that preserves the neighborhood of the partition around $\mathrm{X}$ and registers the intersections between $\mathrm{Y}$ and the tiles around $\mathrm{X}$ (Equation 1). The value of element in the $D_{x y}$ either is empty (With $\Phi$ symbolic representation), either is non-empty (With $\neg \Phi$ symbolic representation). $\mathrm{S}_{\mathrm{NW}}(\mathrm{X})$ expresses the region of the reference object $X$.

$$
D_{X Y}=\left[\begin{array}{lll}
S_{N W}(X) \cap Y & S_{R N}(X) \cap Y & S_{N E}(X) \cap Y \\
S_{R W}(X) \cap Y & S_{S A}(X) \cap Y & S_{R E}(X) \cap Y \\
S_{S W}(X) \cap Y & S_{R S}(X) \cap Y & S_{S E}(X) \cap Y
\end{array}\right]
$$

The direction-relation matrix has nine elements, which yields $2^{9}=512$ possible distinct configurations. However, not all configurations are possible for direction relations. For example, a matrix with all elements having an empty value is impossible, as such a matrix would mean that the target object is absent. A matrix that has a non-empty value in the northwest and southeast elements, and an empty value in all other elements is also impossible (as figure 2), because this implies that the target object is disconnected.

$$
\left[\begin{array}{rrr}
\neg \phi & \phi & \phi \\
\phi & \phi & \phi \\
\phi & \phi & \neg \phi
\end{array}\right]
$$

Fig.2: A matrix impossible for direction relations

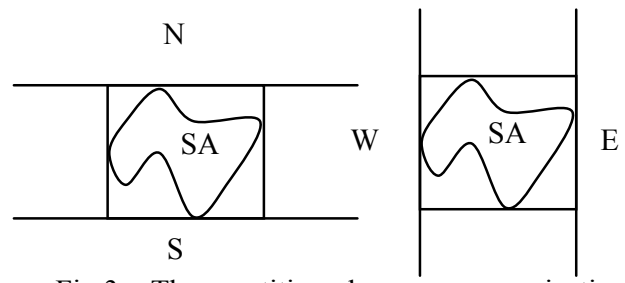

Fig.3: The partition by coarse projection around the reference object.

If we consider the coarse projection around the reference object in $\mathrm{R}^{2}$, we obtain partition shown in figure 3. According to this, we get the set $\mathrm{D}_{4}=\{\mathrm{N}, \mathrm{S}, \mathrm{W}, \mathrm{E}\}$ to represent the north, south, west, east around the reference object. The direction relation in $\mathrm{D}_{4}$ is named weak direction relation that coincides with the definition as follow:

$$
\begin{array}{ll}
\mathrm{N} \equiv_{\text {def }}(\mathrm{NW} \wedge \mathrm{RN} \wedge \mathrm{NE}) & \mathrm{E} \equiv_{\text {def }}(\mathrm{NE} \wedge \mathrm{RE} \wedge \mathrm{SE}) \\
\mathrm{S} \equiv_{\text {def }}(\mathrm{SW} \wedge \mathrm{RS} \wedge \mathrm{SE}) & \mathrm{W} \equiv_{\text {def }}(\mathrm{NW} \wedge \mathrm{RW} \wedge \mathrm{SW})
\end{array}
$$

By all appearances, $\mathrm{D}_{4}$ and $\mathrm{D}_{9}$ can not exactly express the shade in Figure 4, so we define $\mathrm{D}_{8}=\left\{\mathrm{N}_{\mathrm{W}}, \mathrm{N}_{\mathrm{E}}, \mathrm{S}_{\mathrm{W}}, \mathrm{S}_{\mathrm{E}}, \mathrm{W}_{\mathrm{N}}, \mathrm{W}_{\mathrm{S}}, \mathrm{E}_{\mathrm{N}}, \mathrm{E}_{\mathrm{S}}\right\}$ to express north by west, north by east, south by west, south by east, west by north, west by south, east by north, and east by south, called $\mathrm{D}_{8}$ hypo-strong direction relation sets, as Figure 5. For example the shade region of Figure 3 is $\mathrm{N}_{\mathrm{E}}$.

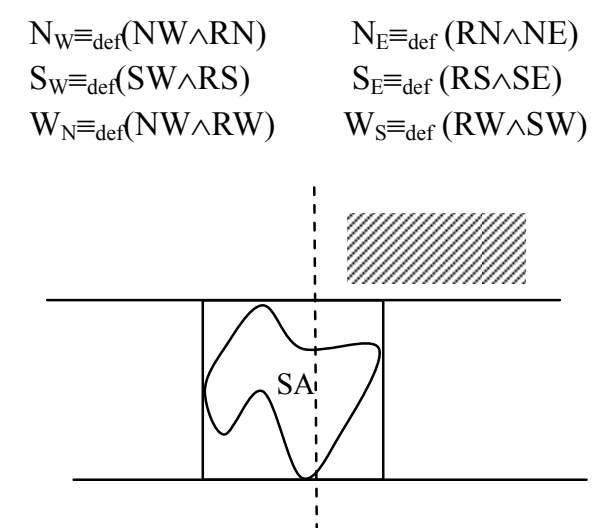

Fig.4: Incapable expression region.
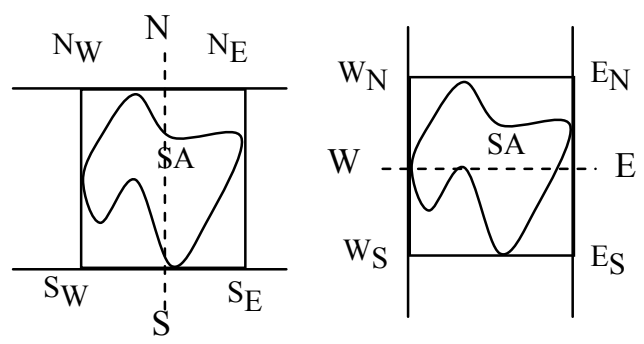

Fig.5: The partition of the projection of $\mathrm{D}_{8}$

$$
\mathrm{E}_{\mathrm{N}} \equiv_{\text {def }}(\mathrm{NE} \wedge \mathrm{RE}) \quad \mathrm{E}_{\mathrm{S}} \equiv_{\text {def }}(\mathrm{RE} \wedge \mathrm{SE})
$$

For reasoning and depiction can be more convenient, we define hypo-strong direction region $\mathrm{M}_{\mathrm{i}}$, $\mathrm{i} \in \mathrm{D}_{8}$ :

$$
\begin{array}{ll}
\mathrm{M}_{\mathrm{NW}}=\mathrm{S}_{\mathrm{NW}} \cup \mathrm{S}_{\mathrm{RN}} & \mathrm{M}_{\mathrm{NE}}=\mathrm{S}_{\mathrm{RN}} \cup \mathrm{S}_{\mathrm{NE}} \\
\mathrm{M}_{\mathrm{SW}}=\mathrm{S}_{\mathrm{SW}} \cup \mathrm{S}_{\mathrm{RS}} & \mathrm{M}_{\mathrm{SE}}=\mathrm{S}_{\mathrm{RS}} \cup \mathrm{S}_{\mathrm{SE}} \\
\mathrm{M}_{\mathrm{WN}}=\mathrm{S}_{\mathrm{NW}} \cup \mathrm{S}_{\mathrm{RW}} & \mathrm{M}_{\mathrm{WS}}=\mathrm{S}_{\mathrm{RW}} \cup \mathrm{S}_{\mathrm{SW}} \\
\mathrm{M}_{\mathrm{EN}}=\mathrm{S}_{\mathrm{NE}} \cup \mathrm{S}_{\mathrm{RE}} & \mathrm{M}_{\mathrm{ES}}=\mathrm{S}_{\mathrm{RE}} \cup \mathrm{S}_{\mathrm{SE}}
\end{array}
$$

The weak direction region $\mathrm{W}_{\mathrm{i}}, \mathrm{i} \in \mathrm{D}_{4}$ :

$$
\begin{array}{ll}
\mathrm{W}_{\mathrm{N}}=\mathrm{S}_{\mathrm{NW}} \cup \mathrm{S}_{\mathrm{RN}} \cup \mathrm{S}_{\mathrm{NE}} & \mathrm{W}_{\mathrm{S}}=\mathrm{S}_{\mathrm{SW}} \cup \mathrm{S}_{\mathrm{RS}} \cup \mathrm{S}_{\mathrm{SE}} \\
\mathrm{W}_{\mathrm{E}}=\mathrm{S}_{\mathrm{NE}} \cup \mathrm{S}_{\mathrm{RE}} \cup \mathrm{S}_{\mathrm{SE}} & \mathrm{W}_{\mathrm{W}}=\mathrm{S}_{\mathrm{NW}} \cup \mathrm{S}_{\mathrm{RW}} \cup \mathrm{S}_{\mathrm{SW}}
\end{array}
$$

The direction relations that can't be represented by strong, hypo-strong or weak direction relations are denoted as nil. Therefore, we can obtain the direction relation set $\mathrm{D}_{22}$ within 22 direction relations:

$$
\begin{aligned}
\mathrm{D}_{22}= & \mathrm{D}_{9} \cup \mathrm{D}_{4} \cup \mathrm{D}_{8} \cup\{\text { nil }\} \\
= & \left\{\mathrm{RN}, \mathrm{NE}, \mathrm{RE}, \mathrm{SE}, \mathrm{RS}, \mathrm{SW}, \mathrm{RW}, \mathrm{NW}, \mathrm{SA}, \mathrm{N}, \mathrm{N}_{\mathrm{W}},\right. \\
& \left.\mathrm{N}_{\mathrm{E}}, \mathrm{S}, \mathrm{S}_{\mathrm{W}}, \mathrm{S}_{\mathrm{E}}, \mathrm{W}, \mathrm{W}_{\mathrm{N}}, \mathrm{W}_{\mathrm{S}}, \mathrm{E}, \mathrm{E}_{\mathrm{N}}, \mathrm{E}_{\mathrm{S}}, \mathrm{nil}\right\}
\end{aligned}
$$

It has been proved that direction relations between spatial objects in $\mathrm{R}^{2}$ represented by $\mathrm{D}_{22}$ have completeness and mutual exclusion. To sum up, $\mathrm{D}_{22}$ coincides with human cognition regarding direction relation, so we use $\mathrm{D}_{22}$ for reasoning in this paper, and direction relation between the reference object $\mathrm{X}$ and the target object $\mathrm{Y}$ can be recorded: $\operatorname{dir}(\mathrm{X}, \mathrm{Y}) \in \mathrm{D}_{22}$.

\section{Lattice array representation with neutral zone}


We represent the direction-relation matrix in the form of a $3 \times 3$ lattice array A (as Figure 6), whose cells correspond to the 9 tiles in projection-based direction model. Among others, $\mathrm{A}_{11}=\mathrm{S}_{\mathrm{NW}}, \mathrm{A}_{12}=\mathrm{S}_{\mathrm{RN}}, \mathrm{A}_{13}=\mathrm{S}_{\mathrm{NE}}$, $\mathrm{A}_{21}=\mathrm{S}_{\mathrm{RW}}, \quad \mathrm{A}_{22}=\mathrm{S}_{\mathrm{SA}}, \quad \mathrm{A}_{23}=\mathrm{S}_{\mathrm{RE}}, \quad \mathrm{A}_{31}=\mathrm{S}_{\mathrm{SW}}, \quad \mathrm{A}_{32}=\mathrm{S}_{\mathrm{RS}}$, $\mathrm{A}_{33}=\mathrm{S}_{\mathrm{SE}}$. In this array, the cell $\mathrm{A}_{\mathrm{ij}}$ is considered to be the MBR of the reference object, so we can label each cell by using strong-direction region $\mathrm{S}_{\mathrm{i}}$, hypo-strong direction region $\mathrm{M}_{\mathrm{i}}$ and each weak-direction region $\mathrm{W}_{\mathrm{i}}$ labels the cell block in array A.

\begin{tabular}{|l|l|l|}
\hline $\mathrm{A}_{11}$ & $\mathrm{~A}_{12}$ & $\mathrm{~A}_{13}$ \\
\hline $\mathrm{A}_{21}$ & $\mathrm{~A}_{22}$ & $\mathrm{~A}_{23}$ \\
\hline $\mathrm{A}_{31}$ & $\mathrm{~A}_{32}$ & $\mathrm{~A}_{33}$ \\
\hline
\end{tabular}

Fig.6 $3 \times 3$ lattice array.

Definition 2: In array D, the cell value is 1 where the value of corresponding element in direction-relation matrix is $\neg \Phi$; the cell value is 0 where the value of corresponding element in direction-relation matrix is $\Phi$.

From Definition 2, given a direction relation $\operatorname{dir}(\mathrm{X}, \mathrm{Y}), \operatorname{dir}(\mathrm{X}, \mathrm{Y}) \in \mathrm{D}_{9}$ or $\operatorname{dir}(\mathrm{X}, \mathrm{Y}) \in \mathrm{D}_{4}$ or $\operatorname{dir}(\mathrm{X}, \mathrm{Y})$ $\in \mathrm{D}_{8}$, we can obtain the lattice array $\mathrm{D}(\mathrm{X}, \mathrm{Y})$. When $\operatorname{dir}(\mathrm{X}, \mathrm{Y})=$ nil, we can't judge the values in the direction-relation matrix because of their variety, so we standardized all values in the matrix to be $\neg \Phi$.

Example 1: Given $\operatorname{dir}(\mathrm{X}, \mathrm{Y})=\mathrm{N}$, the matrix of the relation $\mathrm{N}$ between $\mathrm{X}$ and $\mathrm{Y}$ is $\mathrm{D}_{X Y}$, and the lattice array is $\mathrm{D}(\mathrm{X}, \mathrm{Y})$.

$$
D_{X Y}=\left[\begin{array}{rrr}
\neg & \neg \phi & -\phi \\
\phi & \phi & \phi \\
\phi & \phi & \phi
\end{array}\right] \mathrm{D}(\mathrm{X}, \mathrm{Y})=\begin{array}{|l|l|l|}
1 & 1 & 1 \\
\hline 0 & 0 & 0 \\
\hline 0 & 0 & 0 \\
\hline
\end{array}
$$

Given $\operatorname{dir}(\mathrm{Y}, \mathrm{Z})=\mathrm{NW}$, the matrix of the relation $\mathrm{NW}$ between $Y$ and $Z$ is: $D_{Y Z}$, and the lattice array is $\mathrm{D}(\mathrm{Y}, \mathrm{Z})$.

$$
D_{Y Z}=\left[\begin{array}{ccc}
\neg \phi & \phi & \phi \\
\phi & \phi & \phi \\
\phi & \phi & \phi
\end{array}\right] \quad \mathrm{D}(\mathrm{Y}, \mathrm{Z})=\left[\begin{array}{llll}
\hline 1 & 0 & 0 \\
\hline 0 & 0 & 0 \\
\hline 0 & 0 & 0 \\
\hline
\end{array}\right.
$$

Considering the constraints about 4-connectedness in the lattice array, only a subset of direction-relation arrays may be realized -218 out of $2^{9}=512$ possible combinations, of which the direction relations are concluded into $\mathrm{D}_{22}$.

\section{Combinative reasoning \\ operation}

and

Definition 3: Given $\mathrm{X}, \mathrm{Y}, \mathrm{Z}$ are spatial objects, $\mathfrak{R}$ is complete set of qualitative spatial relations. $\mathrm{R}_{1}, \mathrm{R}_{2}$, $\mathrm{R}_{3} \in \mathfrak{R}$, there is:

$$
\mathrm{R}_{1}(\mathrm{X}, \mathrm{Y}) \circ \mathrm{R}_{2}(\mathrm{Y}, \mathrm{Z})=\left(\mathrm{R}_{1} \circ \mathrm{R}_{2}\right)(\mathrm{X}, \mathrm{Z}) \rightarrow \mathrm{R}_{3}(\mathrm{X}, \mathrm{Z})
$$

called as combinative operation reasoning between $R_{1}$ and $R_{2}$, ' $O$ ' is combinative operator.

From (2) formula, we can gain the rule of spatial relation reasoning:

$$
\text { IF } R_{1}(X, Y) \& R_{2}(Y, Z) \text { THEN } R_{3}(X, Z)
$$

$\mathrm{R}_{1}(\mathrm{X}, \mathrm{Y}) \circ \mathrm{R}_{2}(\mathrm{Y}, \mathrm{Z}), \quad \mathrm{R}_{3}(\mathrm{X}, \mathrm{Z})$ are precondition and conclusion, respectively. Specially, when $\mathfrak{R}$ is complete set of qualitative spatial relations, we can gain the combinative operation of spatial direction relation and the rule of direction relation reasoning.

The method of spatial reasoning based on combinative operation is looking for combinative table [7]. However, forming the large combinative table appears easily mistakes and omissions, and need larger space. Because of the insufficient, a method-qualitative reasoning based on combinative operation between lattice arrays (LAR) that is proposed by us is more intuitionistic and simpler than combinative table reasoning.

\section{Qualitative spatial reasoning based on LAR}

LAR based on the projection model. Firstly, the spatial division is 9 regions (By this kind of $3 \times 3$ form) so as to express the direction relation of $\mathrm{X}$ and $\mathrm{Y}(\operatorname{dir}(\mathrm{X}, \mathrm{Y}))$ and confirm the location of $Y$ to $X$; Secondly, each region division is 16 small regions (By this kind of $4 \times 4$ form) and the core region of $\mathrm{Y}$ should be used to confirm the direction relation of $\mathrm{Y}$ and $\mathrm{Z}(\operatorname{dir}(\mathrm{Y}, \mathrm{Z}))$; Finally, $\operatorname{dir}(\mathrm{X}, \mathrm{Y})$ and $\operatorname{dir}(\mathrm{Y}, \mathrm{Z})$ should be mapped into a $12 \times 12$ lattice array; Finally, the direction relation of $X$ and $\mathrm{Z}(\operatorname{dir}(\mathrm{X}, \mathrm{Z}))$ can be gained by the operation of lattice array. Therefore, LAR could gain the $\operatorname{dir}(X, Z)$ by lattice array operation that is educed by $\operatorname{dir}(\mathrm{X}, \mathrm{Z})$ which is the inference of $\operatorname{dir}(\mathrm{X}, \mathrm{Y})$ and $\operatorname{dir}(\mathrm{Y}, \mathrm{Z})$.

\subsection{Two-time partition embedding space}

Definition 4: in formula (3), the spatial object $X$, which appears in precondition and conclusion as a reference object, is named as master reference object (MRO); the spatial object $\mathrm{Y}$, which only appears in precondition, is named as subsidiary reference object (SRO); the spatial object $\mathrm{Z}$, which appears in conclusion as a target object, is named as master target object (MTO).

SRO is a target object in relation $\operatorname{dir}(\mathrm{X}, \mathrm{Y})$, and a reference object in relation $\operatorname{dir}(\mathrm{Y}, \mathrm{Z})$.

The steps of two-time partition on embedding space are described as follows: 
Step 1: According to $\operatorname{dir}(\mathrm{X}, \mathrm{Y})$, which is the direction relation between MRO and SRO, the lattice array $\mathrm{D}(\mathrm{X}, \mathrm{Y})$ can be obtained by the way introduced in section 3. Those cells in $\mathrm{D}(\mathrm{X}, \mathrm{Y})$ coincide with the first partition $\left(\mathrm{P}_{1}\right)$ on $\mathrm{R}^{2}$ based on the MBR of reference object. So the 9 cells in $\mathrm{D}(\mathrm{X}, \mathrm{Y})$ are considered as strong-direction regions $\mathrm{S}_{\mathrm{i}}$.

Step 2: Partition $R^{2}$ into grid regions $g_{i j}(1 \leq i \leq 12$, $1 \leq \mathrm{j} \leq 12$, which correspond to $12 \times 12$ extended lattice array $G(X, Y)$ shown in figure 7 , where thick lines stand for the first partition $\mathrm{P}_{1}$, and thin lines stand for the second partition $\mathrm{P}_{2}$.

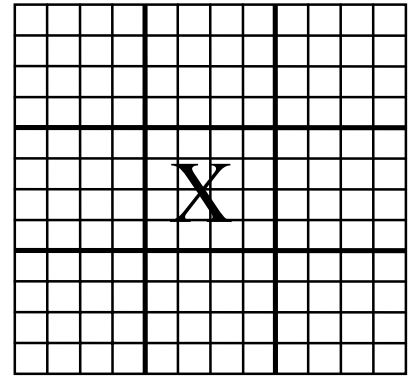

Fig.7: Two-time partition on embedding space.

From $\mathrm{G}(\mathrm{X}, \mathrm{Y}), \mathrm{MBR}_{\mathrm{x}}$ coincides with the cell $\mathrm{G}_{44}$. In terms of the two-time partition, we find these direction regions around $\mathrm{MBR}_{\mathrm{X}}$ in $\mathrm{G}(\mathrm{X}, \mathrm{Y})$ as these cell blocks defined as follows:

$\begin{array}{lc}\mathrm{S}_{\mathrm{NW}}=\left\{\mathrm{g}_{\mathrm{ij}} \mid \mathrm{i} \leq 4, \mathrm{j} \leq 4\right\} & \mathrm{S}_{\mathrm{RN}}=\left\{\mathrm{g}_{\mathrm{ij}} \mid \mathrm{i} \leq 4,5 \leq \mathrm{j} \leq 8\right\} \\ \mathrm{S}_{\mathrm{NE}}=\left\{\mathrm{g}_{\mathrm{ij}} \mid \mathrm{i} \leq 4, \mathrm{j} \geq 9\right\} & \mathrm{S}_{\mathrm{RW}}=\left\{\mathrm{g}_{\mathrm{ij}} \mid 5 \leq \mathrm{i} \leq 8, \mathrm{j} \leq 4\right\} \\ \mathrm{S}_{\mathrm{SA}}=\left\{\mathrm{g}_{\mathrm{ij}} \mid 5 \leq \mathrm{i} \leq 8,5 \leq \mathrm{j} \leq 8\right\} & \mathrm{S}_{\mathrm{RE}}=\left\{\mathrm{g}_{\mathrm{ij}} \mid 5 \leq \mathrm{i} \leq 8, \mathrm{j} \geq 9\right\} \\ \mathrm{S}_{\mathrm{SW}}=\left\{\mathrm{g}_{\mathrm{ij}} \mid \mathrm{i} \geq 9, \mathrm{j} \leq 4\right\} & \mathrm{S}_{\mathrm{RS}}=\left\{\mathrm{g}_{\mathrm{ij}} \mid \mathrm{i} \geq 9,5 \leq \mathrm{j} \leq 8\right\} \\ \mathrm{S}_{\mathrm{SE}}=\left\{\mathrm{g}_{\mathrm{ij}} \mid \mathrm{i} \geq 9, \mathrm{j} \geq 9\right\} & \mathrm{M}_{\mathrm{NW}}=\left\{\mathrm{g}_{\mathrm{ij}} \mid \mathrm{i} \leq 4, \mathrm{j} \leq 6\right\} \\ \mathrm{M}_{\mathrm{NE}}=\left\{\mathrm{g}_{\mathrm{ij}} \mid \mathrm{i} \leq 4, \mathrm{j} \geq 7\right\} & \mathrm{M}_{\mathrm{SW}}=\left\{\mathrm{g}_{\mathrm{ij}} \mid \mathrm{i} \geq 9, \mathrm{j} \leq 6\right\} \\ \mathrm{M}_{\mathrm{SE}}=\left\{\mathrm{g}_{\mathrm{ij}} \mid \mathrm{i} \geq 9, \mathrm{j} \geq 7\right\} & \mathrm{M}_{\mathrm{WN}}=\left\{\mathrm{g}_{\mathrm{ij}} \mid \mathrm{i} \leq 6, \mathrm{j} \leq 4\right\} \\ \mathrm{M}_{\mathrm{WS}}=\left\{\mathrm{g}_{\mathrm{ij}} \mid \mathrm{i} \geq 7, \mathrm{j} \leq 4\right\} & \mathrm{M}_{\mathrm{EN}}=\left\{\mathrm{g}_{\mathrm{ij}} \mid \mathrm{i} \leq 6, \mathrm{j} \geq 9\right\} \\ \mathrm{M}_{\mathrm{ES}}=\left\{\mathrm{g}_{\mathrm{ij}} \mid \mathrm{i} \geq 7, \mathrm{j} \geq 9\right\} & \mathrm{W}_{\mathrm{N}}=\left\{\mathrm{g}_{\mathrm{ij}} \mid \mathrm{i} \leq 4, \mathrm{j} \leq 12\right\} \\ \mathrm{W}_{\mathrm{S}}=\left\{\mathrm{g}_{\mathrm{ij}} \mid \mathrm{i} \geq 9, \mathrm{j} \leq 12\right\} & \mathrm{W}_{\mathrm{W}}=\left\{\mathrm{g}_{\mathrm{ij}} \mid \mathrm{i} \leq 12, \mathrm{j} \leq 4\right\} \\ \mathrm{W}_{\mathrm{E}}=\left\{\mathrm{g}_{\mathrm{ij}} \mid \mathrm{i} \leq 12, \mathrm{j} \geq 9\right\} & \mathrm{R}_{\mathrm{nil}}=\left\{\mathrm{g}_{\mathrm{ij}} \mid \mathrm{i} \leq 12, \mathrm{j} \leq 12\right\} \\ \mathrm{BeC}=\mathrm{is}\end{array}$

Because of the uncertainty of the direction relation nil, we consider it as omni-directional relation, and $R_{\text {nil }}$ is omni-directional region.

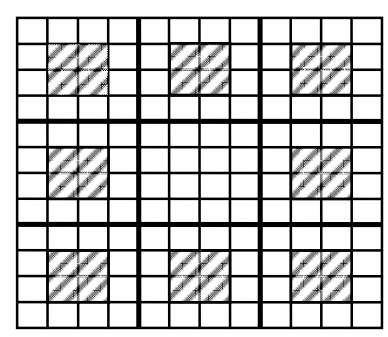

Fig.8: $\mathrm{S}_{\mathrm{i}}{ }^{\prime}$ is marked by shade.

Referring to $\operatorname{dir}(\mathrm{X}, \mathrm{Y})$ and 22 direction regions around $\mathrm{MBR}_{\mathrm{X}}$ in $\mathrm{G}(\mathrm{X}, \mathrm{Y})$, we know the direction region where $\mathrm{Y}$ locates. Considering the shape of $\mathrm{Y}$, we standardize $\mathrm{MBR}_{\mathrm{Y}}$ into grid region $\mathrm{g}_{\mathrm{ij}}$ in order to proceed with the direction reasoning. The standardization makes the core region of direction region replace $\mathrm{MBR}_{\mathrm{Y}}$, and core region is a cell or cell blocks in $\mathrm{G}(\mathrm{X}, \mathrm{Y})$. The core region of $\mathrm{S}_{\mathrm{i}}\left(\mathrm{S}_{\mathrm{i}}{ }^{\prime}\right)$, which is marked by shade in Figure 8 , is a cell in $G(X, Y)$, $\mathrm{S}_{\mathrm{SA}}{ }^{\prime}=\mathrm{MBR}_{\mathrm{X}}=\mathrm{g}_{44}$. The core region of $\mathrm{W}_{\mathrm{i}}\left(\mathrm{W}_{\mathrm{i}}{ }^{\prime}\right)$ is cell blocks in $\mathrm{G}(\mathrm{X}, \mathrm{Y})$ standardized as follows:

$$
\begin{aligned}
& \mathrm{M}_{\mathrm{NW}}{ }^{\prime}=\left\{\mathrm{g}_{\mathrm{ij}} \mid 2 \leq \mathrm{i} \leq 3,2 \leq \mathrm{j} \leq 5\right\} \\
& \mathrm{M}_{\mathrm{NE}}{ }^{\prime}=\left\{\mathrm{g}_{\mathrm{ij}} \mid 2 \leq \mathrm{i} \leq 3,8 \leq \mathrm{j} \leq 11\right\} \\
& \mathrm{M}_{\mathrm{SW}}{ }^{\prime}=\left\{\mathrm{g}_{\mathrm{ij}} \mid 10 \leq \mathrm{i} \leq 11,2 \leq \mathrm{j} \leq 5\right\} \\
& \mathrm{M}_{\mathrm{SE}}{ }^{\prime}=\left\{\mathrm{g}_{\mathrm{ij}} \mid 10 \leq \mathrm{i} \leq 11,8 \leq \mathrm{j} \leq 11\right\} \\
& \mathrm{M}_{\mathrm{WN}}{ }^{\prime}=\left\{\mathrm{g}_{\mathrm{ij}} \mid 2 \leq \mathrm{i} \leq 5,2 \leq \mathrm{j} \leq 3\right\} \\
& \mathrm{M}_{\mathrm{WS}}{ }^{\prime}=\left\{\mathrm{g}_{\mathrm{j} j} \mid 8 \leq \mathrm{i} \leq 11,2 \leq \mathrm{j} \leq 3\right\} \\
& \mathrm{M}_{\mathrm{EN}}{ }^{\prime}=\left\{\mathrm{g}_{\mathrm{ij}} \mid 2 \leq \mathrm{i} \leq 5,10 \leq \mathrm{j} \leq 11\right\} \\
& \mathrm{M}_{\mathrm{ES}}{ }^{\prime}=\left\{\mathrm{g}_{\mathrm{ij}} \mid 8 \leq \mathrm{i} \leq 11,10 \leq \mathrm{j} \leq 11\right\} \\
& \mathrm{W}_{\mathrm{N}}{ }^{\prime}=\left\{\mathrm{g}_{\mathrm{ij}} \mid 2 \leq \mathrm{i} \leq 3,2 \leq \mathrm{j} \leq 11\right\} \\
& \mathrm{W}_{\mathrm{S}}{ }^{\prime}=\left\{\mathrm{g}_{\mathrm{ij}} \mid 10 \leq \mathrm{i} \leq 11,2 \leq \mathrm{j} \leq 11\right\} \\
& \mathrm{W}_{\mathrm{W}}{ }^{\prime}=\left\{\mathrm{g}_{\mathrm{ij}} \mid 2 \leq \mathrm{i} \leq 11,2 \leq \mathrm{j} \leq 3\right\} \\
& \mathrm{W}_{\mathrm{E}}=\left\{\mathrm{g}_{\mathrm{ij}} \mid 2 \leq \mathrm{i} \leq 11,10 \leq \mathrm{j} \leq 11\right\} \\
& \mathrm{R}_{\mathrm{nil}}{ }^{\prime}=\left\{\mathrm{g}_{\mathrm{ij}} \mid 2 \leq \mathrm{i} \leq 11,2 \leq \mathrm{j} \leq 11\right\}
\end{aligned}
$$

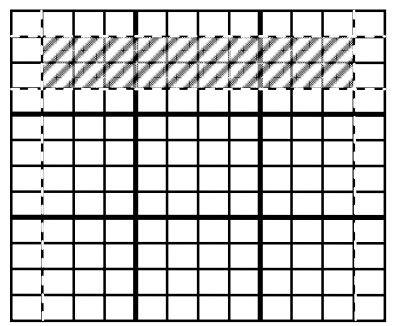

Fig.9: Neutral zone $\mathrm{Q}_{\mathrm{N}}$ '.

The example in Figure 9 shows core region $\mathrm{Q}_{\mathrm{N}}$ ' by shade, 4 dashed around $\mathrm{Q}_{\mathrm{N}}$ ' partition the embedding space into another projection with the neutral zone $R_{N}$ '.

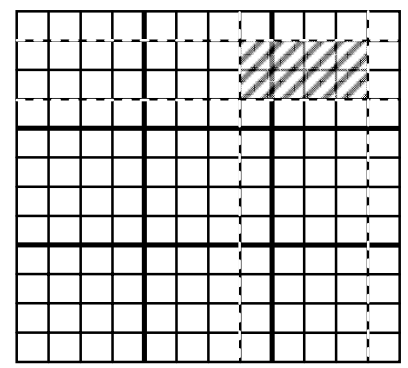

Fig.10: Neutral zone $\mathrm{Q}_{\mathrm{NE}}$ '.

The example in Figure 10 shows core region $\mathrm{Q}_{\mathrm{NE}}$ ' by shade, 4 dashed around $\mathrm{Q}_{\mathrm{NE}}$ ' partition the embedding space into another projection with the neutral zone $\mathrm{R}_{\mathrm{NE}}$ '.

Which makes a preparation for another given condition $\operatorname{dir}(\mathrm{Y}, \mathrm{Z})$. To replace $\mathrm{MBR}_{\mathrm{Y}}$ by core region don't change the quality of $\operatorname{dir}(X, Y)$.

Thus, given $\operatorname{dir}(X, Y) \in D_{22}$, we consider the cell $g_{44}$ in $\mathrm{G}(\mathrm{X}, \mathrm{Y})$ as $\mathrm{MBR}_{\mathrm{X}}$, and use the direction region 
where $\mathrm{Y}$ locates to get the core region as $\mathrm{MBR}_{\mathrm{Y}}$. The approach to arrange MRO and SRO conforms with the value of $\operatorname{dir}(\mathrm{X}, \mathrm{Y})$.

\subsection{Value mapping to extended lattice array $G$}

Given the precondition $\operatorname{dir}(\mathrm{X}, \mathrm{Y})$ and $\operatorname{dir}(\mathrm{Y}, \mathrm{Z})$ in formula (2), of which the values are needed to map into $12 \times 12$ extended lattice arrays $G(X, Y)$, and we can confirm the core lattice cells of $Z$ in $G(X, Y)$ through $\operatorname{dir}(Y, Z)$ to gain $G(X, Z)$. This mapping refers to the MBR of the reference object $X$ and the target object $Y$.

Example 2: given $\operatorname{dir}(X, Y)=N_{E}$, ask for $G(X, Y)$

(1) Referring to $\operatorname{dir}(X, Y)=N_{E}$, in $G(X, Y)$ the direction region $\mathrm{M}_{\mathrm{NE}}{ }^{\prime}=\left\{\mathrm{g}_{\mathrm{ij}} \mid 2 \leq \mathrm{i} \leq 3,9 \leq \mathrm{j} \leq 11\right\}$, values of those grid regions in $\mathrm{M}_{\mathrm{NE}}$ ' are 1 , values of other grid regions are 0, seen in Figure 11.

\begin{tabular}{|l|l|l|l|l|l|l|l|l|l|l|l|}
\hline 0 & 0 & 0 & 0 & 0 & 0 & 0 & 0 & 0 & 0 & 0 & 0 \\
\hline 0 & 0 & 0 & 0 & 0 & 0 & 0 & 1 & 1 & 1 & 1 & 0 \\
\hline 0 & 0 & 0 & 0 & 0 & 0 & 0 & 1 & 1 & 1 & 1 & 0 \\
\hline 0 & 0 & 0 & 0 & 0 & 0 & 0 & 0 & 0 & 0 & 0 & 0 \\
\hline 0 & 0 & 0 & 0 & 0 & 0 & 0 & 0 & 0 & 0 & 0 & 0 \\
\hline 0 & 0 & 0 & 0 & 0 & 0 & 0 & 0 & 0 & 0 & 0 & 0 \\
\hline 0 & 0 & 0 & 0 & 0 & 0 & 0 & 0 & 0 & 0 & 0 & 0 \\
\hline 0 & 0 & 0 & 0 & 0 & 0 & 0 & 0 & 0 & 0 & 0 & 0 \\
\hline 0 & 0 & 0 & 0 & 0 & 0 & 0 & 0 & 0 & 0 & 0 & 0 \\
\hline 0 & 0 & 0 & 0 & 0 & 0 & 0 & 0 & 0 & 0 & 0 & 0 \\
\hline 0 & 0 & 0 & 0 & 0 & 0 & 0 & 0 & 0 & 0 & 0 & 0 \\
\hline 0 & 0 & 0 & 0 & 0 & 0 & 0 & 0 & 0 & 0 & 0 & 0 \\
\hline
\end{tabular}

Fig.11 Values of $\mathrm{G}(\mathrm{X}, \mathrm{Y})$ when $\operatorname{dir}(\mathrm{X}, \mathrm{Y})=\mathrm{N}_{\mathrm{E}}$.

(2) To gain $G(X, Z)$ by $\operatorname{dir}(Y, Z)$ relatives to $G(X, Y)$

We can confirm the core lattice cells of $Z$ in $G(X, Y)$ through $\operatorname{dir}(Y, Z)$ to gain $G(X, Z)$.

We could make sure the core area of $Y$ in the $\mathrm{G}(\mathrm{X}, \mathrm{Y})$ by the values of $\mathrm{G}(\mathrm{X}, \mathrm{Y})$. By the core area of $\mathrm{Y}$ $\left(\mathrm{MBR}_{\mathrm{Y}}\right)$ and $\operatorname{dir}(\mathrm{Y}, \mathrm{Z})$ we can confirm the location of $\mathrm{Z}$ in $\mathrm{G}(\mathrm{X}, \mathrm{Y})$. Values of those grid regions in the location are 1 , values of other grid regions are 0. So this has

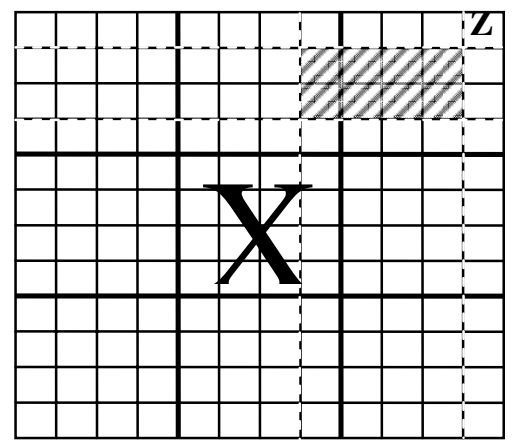

Fig. 12 The configuration about X, Y, Z in example 3 . formed another lattice array $\mathrm{G}(\mathrm{X}, \mathrm{Z})$.

Example 3: Given $\operatorname{dir}(X, Y)=N_{E}, \operatorname{dir}(Y, Z)=N E$, ask for G'(Y,Z).

From example 2, the example in Figure 12 shows the $\mathrm{MBR}_{\mathrm{Y}}$ of $\mathrm{M}_{\mathrm{NE}}$ ' by shade, and the broken line in Figure 12 shows projection model by $\mathrm{MBR}_{\mathrm{Y}}$. Referring to $\operatorname{dir}(\mathrm{Y}, \mathrm{Z})=\mathrm{NE}$, we can confirm the possible grid regions of $Z$, the values of those grid regions of which are 1, values of other grid regions are 0, seen in Figure 13.

\begin{tabular}{|l|l|l|l|l|l|l|l|l|l|l|l|}
\hline 0 & 0 & 0 & 0 & 0 & 0 & 0 & 0 & 0 & 0 & 0 & 1 \\
\hline 0 & 0 & 0 & 0 & 0 & 0 & 0 & 0 & 0 & 0 & 0 & 0 \\
\hline 0 & 0 & 0 & 0 & 0 & 0 & 0 & 0 & 0 & 0 & 0 & 0 \\
\hline 0 & 0 & 0 & 0 & 0 & 0 & 0 & 0 & 0 & 0 & 0 & 0 \\
\hline 0 & 0 & 0 & 0 & 0 & 0 & 0 & 0 & 0 & 0 & 0 & 0 \\
\hline 0 & 0 & 0 & 0 & 0 & 0 & 0 & 0 & 0 & 0 & 0 & 0 \\
\hline 0 & 0 & 0 & 0 & 0 & 0 & 0 & 0 & 0 & 0 & 0 & 0 \\
\hline 0 & 0 & 0 & 0 & 0 & 0 & 0 & 0 & 0 & 0 & 0 & 0 \\
\hline 0 & 0 & 0 & 0 & 0 & 0 & 0 & 0 & 0 & 0 & 0 & 0 \\
\hline 0 & 0 & 0 & 0 & 0 & 0 & 0 & 0 & 0 & 0 & 0 & 0 \\
\hline 0 & 0 & 0 & 0 & 0 & 0 & 0 & 0 & 0 & 0 & 0 & 0 \\
\hline 0 & 0 & 0 & 0 & 0 & 0 & 0 & 0 & 0 & 0 & 0 & 0 \\
\hline
\end{tabular}

Fig.13: Values of $\mathrm{G}^{\prime}(\mathrm{Y}, \mathrm{Z})$ in example 3

\subsection{Reasoning by LAR}

In section 5.2, we obtain the value mapping of $12 \times 12$ lattice array $G(X, Z)$, of which values of those grid regions are 1 is the location of $Z$. The cell $g_{44}$ is looked as $M_{B} R_{X}$ in $G(X, Z)$, so we can get the direction relation $\operatorname{dir}(X, Z)$ by scanning the values of the cells in $\mathrm{G}(\mathrm{X}, \mathrm{Z})$, called algorithm Reverse mapping.

Algorithm: Reverse Mapping;

Input: $\mathrm{G}(\mathrm{X}, \mathrm{Z})$

Output: $\operatorname{dir}(\mathrm{X}, \mathrm{Z}), \operatorname{dir}(\mathrm{X}, \mathrm{Z}) \in \mathrm{D}_{14}$

Steps:

(1) $\operatorname{dir}=\Phi$;

(2) If $\exists i \leq 4,1 \leq j \leq 4, g_{i j}=1$, then $\operatorname{dir} \leftarrow \operatorname{dir} \cup N W$;

(3) If $\exists i \leq 4,5 \leq j \leq 8, g_{i j}=1$, then $\operatorname{dir} \leftarrow \operatorname{dir} \cup R N$;

(4) If $\exists i \leq 4,9 \leq j \leq 12, g_{i j}=1$, then $\operatorname{dir} \leftarrow \operatorname{dir} \cup N E$;

(5) If $\exists 5 \leq i \leq 8,1 \leq j \leq 4, g_{i j}=1$, then $\operatorname{dir} \leftarrow \operatorname{dir} \cup R W$;

(6) If $\exists 5 \leq i \leq 8,5 \leq j \leq 8, g_{i j}=1$, then $\operatorname{dir} \leftarrow \operatorname{dir} \cup S A$;

(7) If $\exists 5 \leq \mathrm{i} \leq 8,9 \leq \mathrm{j} \leq 12, \mathrm{~g}_{\mathrm{ij}}=1$, then $\operatorname{dir} \leftarrow \operatorname{dir} \cup R E$;

(8) If $\exists 9 \leq \mathrm{i} \leq 12,1 \leq \mathrm{j} \leq 4, \mathrm{~g}_{\mathrm{ij}}=1$, then $\operatorname{dir} \leftarrow \operatorname{dir} \cup \mathrm{SW}$;

(9) If $\exists 9 \leq \mathrm{i} \leq 12,5 \leq \mathrm{j} \leq 8, \mathrm{~g}_{\mathrm{ij}}=1$, then $\operatorname{dir} \leftarrow \operatorname{dir} \cup \mathrm{RS}$;

(10) If $\exists 9 \leq \mathrm{i} \leq 12,9 \leq \mathrm{j} \leq 12, \mathrm{~g}_{\mathrm{ij}}=1$, then $\operatorname{dir} \leftarrow \operatorname{dir} \cup \mathrm{SE}$;

(11) If $\mid$ dir $\mid=3$ then \{

if $\operatorname{dir}=\{\mathrm{NW}, \mathrm{RN}, \mathrm{NE}\}$ then $\operatorname{dir}=\{\mathrm{N}\}$;

if $\operatorname{dir}=\{\mathrm{SW}, \mathrm{RS}, \mathrm{SE}\}$ then $\operatorname{dir}=\{\mathrm{S}\}$ 


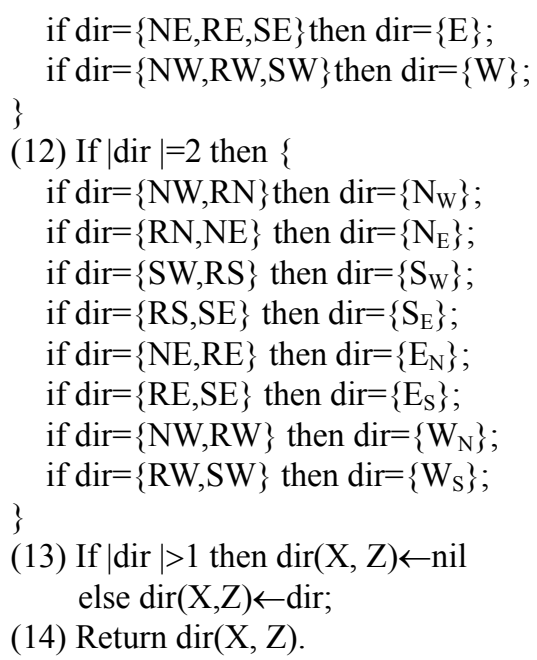

Example 4: Given $\operatorname{dir}(\mathrm{X}, \mathrm{Y})=\mathrm{N}_{\mathrm{E}}, \operatorname{dir}(\mathrm{Y}, \mathrm{Z})=\mathrm{NE}$, ask for $\operatorname{dir}(\mathrm{X}, \mathrm{Z})$

According to the results in example 2 and example 3 , we get the lattice array $G(X, Z)$ shown by Figure 13 . Thus, to call reverse mapping algorithm for $G(X, Z)$, we get $\operatorname{dir}=\{\mathrm{NE}\}$ from step 1 to step 10 .

Traditional GIS uses quantitative representation and reasoning for spatial information. However, the quantitative method to process spatial information is far away from the intuitional reasoning procedure with which human is familiar. In the inference mode of $\operatorname{dir}(\mathrm{X}, \mathrm{Y}) \circ \operatorname{dir}(\mathrm{Y}, \mathrm{Z}) \rightarrow \operatorname{dir}(\mathrm{X}, \mathrm{Z})$, when $\operatorname{dir}(\mathrm{X}, \mathrm{Y}) \in \mathrm{D}_{22}$, $\operatorname{dir}(\mathrm{Y}, \mathrm{Z}) \in \mathrm{D}_{22}$, the conclusion $\operatorname{dir}(\mathrm{X}, \mathrm{Z}) \in \mathrm{D}_{22}$, and the value of $\operatorname{dir}(X, Z)$ is satisfying for human cognition through many instances validation in our research.

\section{Conclusions}

Compared with the popular combinative table reasoning, LAR has some advantages as follows:

(1) In large-scale spaces, the shapes and locations of objects and the distance between objects don't affect the correctness of the reasoning result, which conforms to the correctness and universality of reasoning mode.

(2) The lattice array representation for direction relation simplifies the complexity of spatial problems. That the algebra operation is employed for the combinative operation between lattice arrays can improve the efficiency to judge the direction relation between objects.

(3) LAR embodies the intuitional reasoning process of human cognition.

The conception of direction in human cognition not only relates to the locations of the objects, but also relates to the shapes of the objects and the reference frame. That is, the conception of direction depends on circumstance. This paper uses projection-based direction model with neutral zone, and let MBR replace reference object and target object, which has wide applicability for area objects and line objects. Considering the situation with enough large scale, the point objects are materialized as area objects, so the reasoning process is able to complete for all spatial objects in $\mathrm{R}^{2}$ with large-scale spaces.

\section{References}

[1] J. Chen and R.L. Zhao, The basic problems and research progress on the spatial relations of GIS, Acta Geodaetica et Cartographica Sinica(in Chinese), 28(2):95-102, 1999.

[2] Y.B. Liu and D.W. Liu, The qualitative spatial representation and the research progress on qualitative space, Computer science (in Chinese), 30(3):65-67, 2003.

[3] S.Z. Liao and C.Y. Shi, The Research and progress on qualitative spatial reasoning, Computer science (in Chinese), 25(4):11-13, 1998.

[4] H. Cao and J. Chen, The Qualitative description and reasoning on direction relation and distance relation, Journal of Xi'An Petroleum Institute (Natural Science Edition), 16(1):68-72, 2001.

[5] A.G. Cohn, B. Bennett, J. Gooday and N. M. Gotts, Qualitative spatial representation and reasoning with the region connection calculus, GeoInformatica, 1:275-316, 1997.

[6] A.U. Frank, Qualitative spatial reasoning: cardinal directions as an example, International Journal of Geographical Information Science, 10:269-290, 1996.

[7] R.K. Goyal, Similarity assessment for cardinal directions between extended spatial objects, Ph.D. Thesis, University of Maine, 2000. 